\title{
Patients with Somatic Illness and Accompanying Psychomental Health Problems have Similar Psychological Capacity Impairments Like Patients with Mental Disorders
}

\section{Beate Muschalla ( $\boldsymbol{\sigma}$ b.muschalla@tu-braunschweig.de )}

Technische Universität Braunschweig: Technische Universitat Braunschweig https://orcid.org/00000001-5285-6618

Michael Jöbges

Schmieder Hospitals - Hospital Konstanz: Kliniken Schmieder Konstanz

Short report

Keywords: Somatic illness, chronic illness, psychomental health, capacities, comorbidities, ICF

Posted Date: December 1st, 2020

DOI: https://doi.org/10.21203/rs.3.rs-115426/v1

License: (c) (i) This work is licensed under a Creative Commons Attribution 4.0 International License.

Read Full License 


\section{Abstract}

Background: In patients with somatic illness and additional psychomental health problem, not only motor or sensory functions may be impaired, but also psychological skills which become more and more important for work ability in our modern working world. There are presently no data about the type and distribution of capacity impairments in patients with comorbid somatic and psychomental health problems. These data are however important for estimation of diagnostic and therapy requirements. This research thus investigates capacity impairment in patients who suffer from mixed somatic and mental health problems. Research questions are: (1) How many of patients with comorbid somatic and mental disorders suffer from clinically relevant capacity impairments according to Mini-ICF-APP? and (2) Do patients with different somatic diseaeses have different capacity impairments?

Methods: 402 patients with comorbid mental and somatic health problems (out of 1016 screened patients) were in depth investigated in a clinical interview for mental disorders (MINI) and capacity limitations (Mini-ICF-APP).

Results: At least half of the patients had any clinically relevant capacity impairment. Neurology patients $(67 \%)$ and orthopedic patients (72\%) were more often affected than cardiology patients $(50.5 \%)$. Orthopedic patients are slightly more impaired in self-care, neurology and orthopedic patients are more impaired in mobility, and cardiology patients are less impaired in assertiveness.

Conclusion: In comparison to patients with chronic mental health problems the number of capacity impairments is similar. The data from this study are important in order to estimate diagnostic and therapeutic needs in respect to capacity training or compensation of capacity impairments.

\section{Introduction}

Mental health problems occur in about one-fourth of the general population. They are often chronic, and coming along with severe and enduring work performance problems [1]. A similar amount of patients with somatic diseases suffer from comorbid mental disorders [2].

In some cases, these are true comorbidities, i.e. independent mental disorders which in most cases have already been present for a long time and even before the somatic illness. In other cases, mental health problems occur as a by-phenomenon due to a somatic illness, e.g. problems in affect regulation after a stroke or heart infarction, or anxiety which may arise after acute somatic event or acute treatment [3].

In patients with somatic illness and additional psychomental health problem, not only motor or sensory functions may be impaired, but also psychological skills which become more and more important for work ability in most jobs [4]. There are presently no data about the type and distribution of capacity impairments in patients with comorbid somatic and psychomental health problems. These data are however important for estimation of diagnostic and therapy requirements. Furthermore, description of type and degree of psychomental capacity limitations is essentially for work ability description, which is 
an important task in rehabilitation medicine. This research takes a first step to fill this gap by investigating capacity impairment in patients who suffer from mixed somatic and mental health problems at the same time.

\section{Objectives}

1. How many of patients with comorbid somatic and mental disorders suffer from clinically relevant capacity impairments according to Mini-ICF-APP?

2. Do patients with different somatic diseaeses have different capacity impairments?

\section{Methods}

\section{Study design}

In order to investigate patients with somatic and mental health problems, all incoming patients in three clinics (cardology, orthopaedy, neurology) were seen in a short screening interview. They were asked for present and lifetime mental disorders (MINI [5]), and if there were mental health problems, the patients were additionally investigated concerning capacity impairments according to the observer rating Mini-ICFAPP [6]. These assessments lasted about 60 minutes and were all conducted by the same behavior therapist who had more than ten years of training in rehabilitation medicine and diagnostic of capacity limitations. The diagnosticer's observer rating on the Mini-ICF-APP was based on information gathered from the participants in the structured interview [6] and from the illness-related assessment [5]. This is according to the rules for good practice in social-medicine decisions and work ability descriptions. Therefore, this capacity diagnostic is both objective and of high ecological validity and standard.

Patients participated in this study with written informed consent. The study was reviewed and approved by the ethics and data protection committee of the [agency blinded for review].

\section{Instruments}

Capacity limitations assessed with Mini-ICF-APP. The Mini-ICF-APP (6) is an observer rating instrument that is internationally evaluated [7] and established in social medicine [8,9] to measure capacity limitations in the context of mental disorders. It offers a selection of capacity dimensions derived from the WHO's International Classification of Functioning, Disability and Health, ICF. The Mini-ICF-APP capacity limitations rating is observer rated and the usual time frame is the last two weeks. Thirteen domains of capacity are assessed: (1) adherence to regulations, (2) planning and structuring tasks, (3) flexibility, (4) applying expertise, (5) capacity to judge and decide, (6) endurance, (7) assertiveness, (8) contacts with others, (9) teamwork and group interaction capacity (10) dyadic relationships, (11) proactivity, (12) self-care, and (13) mobility. Each dimension is rated on a five-point Likert scale: $0=$ no limitations, 1 = mild limitations without problems in the environmental context, 2 = moderate limitations causing problems in the environment, 3 = severe limitations causing problems and the necessity for 
assistance, and 4 = total limitations and exemption from all specific role duties in the context of reference. Anchor definitions for each item are provided in the rating manual [6]. The rating uses all available information including the participant's self-report, case record and observation from the interview situation. Inter-rater reliability varies from $r=.70$ (untrained raters) to $r=.90$ (trained raters) [6]. The Mini-ICF-APP has been validated with the Groningen Social Disability Interview [10]. The Mini-ICFAPP rating in this present study was conducted with reference to the present work context of the participant (e.g. present workplace, or - if presently unemployed - any workplace on the general labour market). The choice of this context is according to the social medicine routine for work ability assessment in rehabilitation clinics.

Patients characteristics. Participants were asked for their cumulated sick leave duration in the past twelve months in weeks. They were explored in terms of mental disorders according to DSM criteria by means of the established Mini International Neuropsychiatric (MINI) interview [5], which covers the broad range of common mental disorders (anxiety, depression, adjustment, addiction, personality disorder).

\section{Statistical analysis}

Data were analyzed with SPSS. Descriptive statistics (Table 1), and group comparisons by analysis of variance (ANOVA, with Bonferroni correction) or $\mathrm{Chi}^{2}$-Test (Table 2) were calculated. 
Table 1

Characteristics and capacity imparments of patients from different somatic indications who suffer from chronic mental health problems. Means (standard deviation) for continuous variables are reported. Percentages for frequencies of clinically relevant impairment (capacity impairment rating 3 or 4) and means of impairment (standard deviation) are reported. Chi ${ }^{2}$-Test and ANOVA (Overall analysis, and Post-Hoc tests with Bonferroni correction for multiple testing) have been calculated.

\begin{tabular}{|c|c|c|c|c|c|}
\hline & $\begin{array}{l}\text { Cardiology } \\
(n=106)\end{array}$ & $\begin{array}{l}\text { Orthopaedy } \\
(n=64)\end{array}$ & $\begin{array}{l}\text { Neurology } \\
(n=232)\end{array}$ & $\begin{array}{l}\text { All } \\
(\mathrm{N}= \\
402)\end{array}$ & $\begin{array}{l}\text { Significance } \\
\text { of } \\
\text { difference } \\
\text { between the } \\
\text { groups } \\
\text { (ANOVA, } X^{2} \text { ) } \\
p\end{array}$ \\
\hline Gender male & $70.8 \%$ & $18.8 \%$ & $48.7 \%$ & $49.8 \%$ & .000 \\
\hline Age & $\begin{array}{l}52.42 \\
(6.60)\end{array}$ & $\begin{array}{l}50.80 \\
(8.08)\end{array}$ & $\begin{array}{l}49.30 \\
(8.91)\end{array}$ & $\begin{array}{l}50.36 \\
(8.32)\end{array}$ & $\begin{array}{l}\text { overall test: } \\
.005 \\
\text { Pairwise } \\
\text { comparisons: } \\
\text { CvsN .004 }\end{array}$ \\
\hline $\begin{array}{l}\text { Sick leave duration past } 12 \\
\text { months in weeks }\end{array}$ & $\begin{array}{l}8.42 \\
(14.74)\end{array}$ & $\begin{array}{l}20.39 \\
(21.13)\end{array}$ & $\begin{array}{l}7.86 \\
(15.33)\end{array}$ & $\begin{array}{l}10.00 \\
(16.82)\end{array}$ & 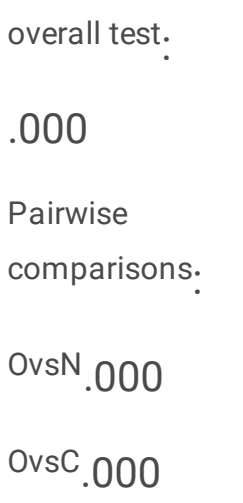 \\
\hline $\begin{array}{l}\text { Disability pension } \\
\text {-planned } \\
\text {-applied for }\end{array}$ & $\begin{array}{l}13.2 \% \\
3.8 \%\end{array}$ & $\begin{array}{l}21.9 \% \\
14.1 \%\end{array}$ & $\begin{array}{l}6.9 \% \\
5.2 \%\end{array}$ & $\begin{array}{l}10.9 \% \\
6.2 \%\end{array}$ & .000 \\
\hline Presently employed & $77.1 \%$ & $70.3 \%$ & $84.8 \%$ & $80.5 \%$ & .021 \\
\hline $\begin{array}{l}\text { Number of lifetime mental } \\
\text { disorders according to MINI }\end{array}$ & $\begin{array}{l}0.91 \\
(1.16)\end{array}$ & $\begin{array}{l}1.14 \\
(1.45)\end{array}$ & $\begin{array}{l}1.25 \\
(1.46)\end{array}$ & $\begin{array}{l}1.14 \\
(1.39)\end{array}$ & .074 \\
\hline $\begin{array}{l}\text { Mini-ICF-APP capacity } \\
\text { dimensions (impairment } \\
\text { degrees were rated } 0-4 \text { ) }\end{array}$ & & & & & \\
\hline
\end{tabular}




\begin{tabular}{|c|c|c|c|c|c|}
\hline & $\begin{array}{l}\text { Cardiology } \\
(n=106)\end{array}$ & $\begin{array}{l}\text { Orthopaedy } \\
(n=64)\end{array}$ & $\begin{array}{l}\text { Neurology } \\
(n=232)\end{array}$ & $\begin{array}{l}\text { All } \\
(\mathrm{N}= \\
402)\end{array}$ & $\begin{array}{l}\text { Significance } \\
\text { of } \\
\text { difference } \\
\text { between the } \\
\text { groups } \\
\text { (ANOVA, } X^{2} \text { ) } \\
p\end{array}$ \\
\hline Adherence to regulations & $\begin{array}{l}0.59 \\
(0.82) \\
2.8 \%\end{array}$ & $\begin{array}{l}0.92(0.96) \\
6.3 \%\end{array}$ & $\begin{array}{l}0.83 \\
(0.96) \\
7.7 \%\end{array}$ & $\begin{array}{l}0.78 \\
(0.93) \\
6.2 \%\end{array}$ & $\begin{array}{l}\text { Overall } .038 \\
X^{2} .230\end{array}$ \\
\hline Planning and structuring tasks & $\begin{array}{l}0.70 \\
(0.85) \\
5.7 \%\end{array}$ & $\begin{array}{l}0.83(0.81) \\
3.1 \%\end{array}$ & $\begin{array}{l}1.00 \\
(0.97) \\
9.9 \%\end{array}$ & $\begin{array}{l}0.89 \\
(0.93) \\
7.7 \%\end{array}$ & $\begin{array}{l}\text { Overall } .020 \\
\text { CvsN } .020 \\
X^{2} .135\end{array}$ \\
\hline Flexibility & $\begin{array}{l}1.41 \\
(1.04) \\
15.2 \%\end{array}$ & $\begin{array}{l}1.94(0.85) \\
25.0 \%\end{array}$ & $\begin{array}{l}1.67 \\
(0.96) \\
22.3 \%\end{array}$ & $\begin{array}{l}1.65 \\
(0.98) \\
20.9 \%\end{array}$ & $\begin{array}{l}\text { Overall } .002 \\
\text { Cvso } .002 \\
X^{2} .226\end{array}$ \\
\hline Capacity to judge and decide & $\begin{array}{l}1.25 \\
(1.05) \\
15.2 \%\end{array}$ & $\begin{array}{l}1.69(1.02) \\
17.2 \%\end{array}$ & $\begin{array}{l}1.50 \\
(0.99) \\
17.8 \%\end{array}$ & $\begin{array}{l}1.47 \\
(1.02) \\
17.0 \%\end{array}$ & $\begin{array}{l}\text { Overall } .016 \\
\text { Cvso } .019 \\
X^{2} .843\end{array}$ \\
\hline Endurance & $\begin{array}{l}1.76 \\
(1.04) \\
26.4 \%\end{array}$ & $\begin{array}{l}1.86(1.06) \\
28.6 \%\end{array}$ & $\begin{array}{l}1.92 \\
(1.08) \\
36.8 \%\end{array}$ & $\begin{array}{l}1.87 \\
(1.07) \\
32.8 \%\end{array}$ & $\begin{array}{l}\text { Overall } .470 \\
X^{2} .126\end{array}$ \\
\hline Contacts with others & $\begin{array}{l}0.68 \\
(0.99) \\
5.7 \%\end{array}$ & $\begin{array}{l}0.89(0.98) \\
3.1 \%\end{array}$ & $\begin{array}{l}0.69 \\
(0.95) \\
6.0 \%\end{array}$ & $\begin{array}{l}0.72 \\
(0.97) \\
5.5 \%\end{array}$ & $\begin{array}{l}\text { Overall .296 } \\
X^{2} .081\end{array}$ \\
\hline Teamwork capacity & $\begin{array}{l}0.71 \\
(1.13) \\
8.6 \%\end{array}$ & $\begin{array}{l}1.23(1.27) \\
14.0 \%\end{array}$ & $\begin{array}{l}0.86 \\
(1.05) \\
6.9 \%\end{array}$ & $\begin{array}{l}0.88 \\
(1.12) \\
8.5 \%\end{array}$ & $\begin{array}{l}\text { Overall } .012 \\
\text { Cvso } .010 \\
X^{2} .190\end{array}$ \\
\hline Assertiveness & $\begin{array}{l}1.26 \\
(1.14) \\
16.2 \%\end{array}$ & $\begin{array}{l}1.78(1.17) \\
28.1 \%\end{array}$ & $\begin{array}{l}1.41 \\
(1.21) \\
26.7 \%\end{array}$ & $\begin{array}{l}1.43 \\
(1.20) \\
24.2 \%\end{array}$ & $\begin{array}{l}\text { Overall } .021 \\
\text { Cvs0 } .017 \\
X^{2} .081\end{array}$ \\
\hline
\end{tabular}




\begin{tabular}{|c|c|c|c|c|c|}
\hline & $\begin{array}{l}\text { Cardiology } \\
(n=106)\end{array}$ & $\begin{array}{l}\text { Orthopaedy } \\
(n=64)\end{array}$ & $\begin{array}{l}\text { Neurology } \\
(n=232)\end{array}$ & $\begin{array}{l}\text { All } \\
\left(\begin{array}{l}N= \\
402)\end{array}\right.\end{array}$ & $\begin{array}{l}\text { Significance } \\
\text { of } \\
\text { difference } \\
\text { between the } \\
\text { groups } \\
\text { (ANOVA, } X^{2} \text { ) } \\
p\end{array}$ \\
\hline Mobility & $\begin{array}{l}0.31 \\
(0.79) \\
4.7 \%\end{array}$ & $\begin{array}{l}0.84(1.16) \\
15.6 \%\end{array}$ & $\begin{array}{l}0.65 \\
(1.07) \\
10.3 \%\end{array}$ & $\begin{array}{l}0.59 \\
(1.03) \\
9.7 \%\end{array}$ & $\begin{array}{l}\text { Overall .002 } \\
\text { CvsO } .003 \\
\text { CvsN } .014 \\
X^{2} .058\end{array}$ \\
\hline Applying expertise & $\begin{array}{l}0.94(1.1) \\
14.3 \%\end{array}$ & $\begin{array}{l}1.38(1.23) \\
25.0 \%\end{array}$ & $\begin{array}{l}1.30 \\
(1.15) \\
19.8 \%\end{array}$ & $\begin{array}{l}1.22 \\
(1.16) \\
19.2 \%\end{array}$ & $\begin{array}{l}\text { Overall } .016 \\
\text { CvsN } .025 \\
X^{2} .214\end{array}$ \\
\hline Proactivity & $\begin{array}{l}0.56 \\
(0.78) \\
1.9 \%\end{array}$ & $\begin{array}{l}0.88(0.93) \\
6.3 \%\end{array}$ & $\begin{array}{l}0.72 \\
(0.88) \\
5.2 \%\end{array}$ & $\begin{array}{l}0.71 \\
(0.87) \\
4.5 \%\end{array}$ & $\begin{array}{l}\text { Overall } .067 \\
X^{2} .309\end{array}$ \\
\hline $\begin{array}{l}\text { Dyadic (familiar and intimate) } \\
\text { relationships }\end{array}$ & $\begin{array}{l}0.56 \\
(0.88) \\
3.8 \%\end{array}$ & $\begin{array}{l}0.70(0.90) \\
3.1 \%\end{array}$ & $\begin{array}{l}0.60 \\
(0.81) \\
0.9 \%\end{array}$ & $\begin{array}{l}0.61 \\
(0.84) \\
2.0 \%\end{array}$ & $\begin{array}{l}\text { Overall .564 } \\
X^{2} .159\end{array}$ \\
\hline Self care & $\begin{array}{l}0.42 \\
(0.78) \\
1.9 \%\end{array}$ & $\begin{array}{l}0.67(0.93) \\
6.2 \%\end{array}$ & $\begin{array}{l}0.40 \\
(0.68) \\
1.7 \%\end{array}$ & $\begin{array}{l}0.45 \\
(0.75) \\
2.5 \%\end{array}$ & $\begin{array}{l}\text { Overall .031 } \\
\text { OvsN .028 }\end{array}$ \\
\hline $\begin{array}{l}\text { Any clinically relevant capacity } \\
\text { impairment }\end{array}$ & $50.5 \%$ & $71.9 \%$ & $67.0 \%$ & $63.5 \%$ & $x^{2} .004$ \\
\hline $\begin{array}{l}\text { Mini-ICF-APP capacity } \\
\text { limitations mean }\end{array}$ & $\begin{array}{l}0.88 \\
(0.65)\end{array}$ & $1.20(0.63)$ & $\begin{array}{l}1.05 \\
(0.61)\end{array}$ & $\begin{array}{l}1.03 \\
(0.63)\end{array}$ & $\begin{array}{l}\text { Overall .004 } \\
\text { OvsC .003 } \\
\text { OvsN .056 }\end{array}$ \\
\hline
\end{tabular}

\section{Results}

\section{Participants' characteristics}

From initially screened 1610 patients (505 cardiology, 290 orthopaedy, 815 neurology, Table 1), 402 patients reported additional psychomental health problems and could be interviewed in depth concerning 
capacity impairments. Patients with orthopedic diseases had most often applied for disability pension, had longer past sick leave durations, and were mostly women. Cardiology patients were most often men. Number of mental disorders was similarly distributed in the three indications. There were tendentially more often hypochondriasis and agoraphobia, i.e. anxiety syndromes with avoidance behavior, in orthopedic patients.

\section{Frequencies Of Clinically Relevant Capacity Disorders}

Clinically relevant capacity impairments occur when an impairment has reached a quality which make assistance by thirds necessary. In the Mini-ICF-APP assessments, clinically relevant impairmants are those rated with " $3=$ assistance is needed in order to fulfill the activities related to this capacity" or " $4=$ complete impairment". In all three somatic indications at least half of the patients had any clinically relevant capacity impairment. Neurology patients $(67 \%)$ and orthopedic patients $(72 \%)$ were more often affected than cardiology patients (50.5\%) (Table 2).

\section{Types Of Capacity Limitations In Different Somatic Diseases}

Capacity impairments vary slightly, but are on average rather similarly distributed in the three groups of patients. None of the three groups has consistently increased capacity impairments in comparison to the others. There is a tendency that orthopedic patients are slightly more impaired in self-care, neurology and orthopedic patients more impaired in mobility, and cardiology patients are less impaired in assertiveness.

\section{Discussion}

The here investigated typical general population patients with somatic diseases who suffer from comorbid mental health problems have in $50-70 \%$ of cases relevant psychomental capacity impairments. The type of capacity impairment is rather independent from the type of somatic illness. In comparison to patients with chronic mental health problems the number of capacity impairments is similar [6].

In contrast to patients with mental disorders only (i.e. those without somatic comorbidity), the impairment quality in comorbid patients can be partly influenced by the somatic illness. For example, an agoraphobic patient cannot use the bus because $s /$ he is afraid of a panic attack (anxiety problem). An orthopedic patient may be unable to use the bus because s/he cannot step in (somatic problem), OR because $s /$ he is afraid that s/he cannot step in (somatic-associated anxiety problem), OR because $\mathrm{s} / \mathrm{he}$ is afraid of a panic attack (anxiety problem). Thus, in comorbid patients, mental and somatic diagnostic levels must be differentiated. 
This study is a cross-sectional observation study and thus lacks an investigation of capacity impairments over the course of illness development. Further research should investigate whether and to which degree capacity impairments may decrease when the somatic or the mental illness (or both) is remitting.

\section{Conclusion}

The findings from this study are important as they can help to estimate diagnostic and therapeutic needs in respect to capacity training or compensation of capacity impairments in patients with chronic illness. The Mini-ICF-APP makes it possible to describe type and degree of psychomental capacity limitations, which is an essential aspect in work ability decisions and descriptions [11].

\section{Abbreviations}

DSM

Diagnostic and Statistical Manual for Mental Disorders

ICF

International Classification of Functioning, Disability and Health

Mini-ICF-APP

Observer rating for psychomental capacity impairments

MINI

Mini International Neuropsychiatric Interview

\section{Déclarations}

Ethics approval and consent to participate: Patients participated in this study with written informed consent. All procedures performed in this study involving human participants were in accordance with the ethical standards of the institutional and/or national research committee

and with the 1964 Helsinki Declaration and its later amendments or comparable ethical standards. The study was reviewed and approved by the ethics and data protection committee of the [agency blinded for review].

Consent for publication: Not applicable

Availablility of data and materials: Data are available from the corresponding author.

Competing interests: The authors declare that they have no conflicts of interest.

Funding: This research has been funded by a research grant from the [agency blinded for review]

Authors contribution: B.M. attracted the study's funding, planned and conducted the study, analysed the data and wrote the manuscript. M.J. assisted study conduction and added content to the manuscript. 
Acknowledgment: The manuscript underwent English language proofreading by Kelly GmbH.

\section{References}

1. Stansfeld SA, Clark C, Caldwell T, Rodgers B, Power C. Psychosocial work characteristics and anxiety and depressive disorders in midlife: the effects of prior psychological distress. Occup Environ Med. 2008;65:634-42. doi:10.1136/oem.2007.036640.

2. Angermann CE, Ertl G. Depression, Anxiety, and Cognitive Impairment. Comorbid Mental Health Disorders in Heart Failure. Curr Heart Fail Rep. 2018;15:398-410. doi:10.1007/s11897-018-0414-8.

3. Linden M, Muschalla B. Standardized diagnostic interviews, criteria, and algorithms for mental disorders: garbage in, garbage out. Eur Arch Psychiatry Clin Neurosci. 2012;262:535-44.

4. Harvey SB, Modini M, Joyce S, Milligan-Saville JS, Tan L, Mykletun A, et al. Can work make you mentally ill? A systematic meta-review of work-related risk factors for common mental health problems. Occup Environ Med. 2017;74:301-10. doi:10.1136/oemed-2016-104015.

5. Sheehan D, Lecrubier Y, Sheehan H, Amorim P, Janavs J, Weiller E, et al. The Mini International Neuropsychiatric Interview: the development and validation of a structured diagnostic psychiatric interview for DSM-IV and ICD-10 1998. J Clin Psychiatry. 1998;59:22-33.

6. Linden M, Baron S, Muschalla B. Mini-ICF-Rating für psychische Störungen (Mini-ICF-APP). Ein Kurzinstrument zur Beurteilung von Fähigkeits- bzw. Kapazitätsstörungen bei psychischen Störungen. [A short rating for capacity limitations in mental disorders (Mini-ICF-APP)]. Göttingen: Hans Huber; 2009, 2015.

7. Pinna F, Fiorillo A, Tusconi M, Guiso B, Carpiniello. Assessment of functioning in patients with schizophrenia and schizoaffective disorders with the Mini-ICF-APP: a validation study in Italy. Int $J$ Men Health Syst. 2015;9:37. doi:10.1186/s13033-015-0030-x.

8. DRV. Leitlinien für die sozialmedizinische Begutachtung. Sozialmedizinische Beurteilung bei psychischen und Verhaltensstörungen. Berlin: Deutsche Rentenversicherung Bund; 2012.

9. SGPP. Qualitätsleitlinien für psychiatrische Gutachten in der Eidgenössischen Invalidenversicherung. Bern: Schweizerische Gesellschaft für Psychiatrie und Psychotherapie und Schweizerische Gesellschaft für Versicherungspsychiatrie; 2012.

10. Wiersma D, DeJong A, Kraaijkamp HJM, Ormel J. The Groningen Social Disability Schedule. Manual and Questionnaires. Second Version. University of Groningen: Department of Social Psychiatry; 1990.

11. AWMF. Leitlinie zur Begutachtung bei psychischen und psychosomatischen Störungen. [Guideline for social medicine assessment in mental and psychosomatic illness.] Günzburg: Arbeitsgemeinschaft der Wissenschaftlichen Medizinischen Fachgesellschaften; 2019. 